\title{
Study of Thermoplastic Extrusion and Its Impact on the Chemical and Nutritional Characteristics and Two Sorghum Genotypes SC 319 and BRS 332
}

\author{
Flávia A. Campelo, ${ }^{a}$ Gilberto S. Henriques, ${ }^{b}$ Maria Lucia F. Simeone, ${ }^{\circledR c}$ \\ Valéria A. V. Queiroz, ${ }^{d}$ Mauro R. Silva, ${ }^{a}$ Rodinei Augusti, ${ }^{\oplus e}$ Júlio O. F. Melo, ${ }^{\circledR} *, f$ \\ Inayara C. A. Lacerda ${ }^{a}$ and Raquel L. B. Araújo ${ }^{a}$ \\ ${ }^{a}$ Departamento de Alimentos, Universidade Federal de Minas Gerais (UFMG), \\ 31270-901 Belo Horizonte-MG, Brazil \\ ${ }^{b}$ Departamento de Nutrição, Universidade Federal de Minas Gerais (UFMG), \\ 30130-100 Belo Horizonte-MG, Brazil \\ ${ }^{c}$ Departamento de Agroquímica, Embrapa Milho e Sorgo, Rodovia MG 424, $\mathrm{km} 45$, \\ 35702-098 Sete Lagoas-MG, Brazil \\ ${ }^{d}$ Departamento de Segurança Alimentar, Embrapa Milho e Sorgo, Rodovia MG 424, km 45, \\ 35702-098 Sete Lagoas-MG, Brazil \\ ${ }^{e}$ Departamento de Química, Universidade Federal de Minas Gerais (UFMG), \\ 31270-901 Belo Horizonte-MG, Brazil \\ ${ }^{f}$ Departamento de Ciências Exatas e Biológicas, Universidade Federal de São João Del-Rei (UFSJ), \\ 35701-970 Sete Lagoas-MG, Brazil
}

\begin{abstract}
The use of sorghum in human nutrition has been expanded due to its nutritional composition and its functional potential. Extrusion has been used to improve the quality of sorghum. The aim of this work was to assess the effect of extrusion in the nutritional composition, phenolic compounds content of two sorghum, and characterize the profile of chemical constituents by paper spray mass spectrometry (PS-MS). Extrusion increased the carbohydrate and fiber contents and reduced moisture, lipids and ashes, and enabling a higher degree of liberation of phenolic compounds and antioxidant activity. The fingerprint obtained in both ionization modes had been influenced by extrusion, allowing for a greater compounds' identification on the extruded samples. The analysis of sorghum samples' main components made distinguishing of the main constituents possible, as well as highlighted the extrusion effect and the influence of the genotypes. This study demonstrated that extrusion enabling a higher liberation of phenolic compounds, which were identified by the PS-MS technique.
\end{abstract}

Keywords: sorghum genotype, extrusion, paper spray, principal components analysis

\section{Introduction}

Sorghum is the fifth largest crop in the world, used particularly for animal feeding, as in Brazil. However, in semi-arid regions, such as Africa and Asia, this cereal is largely used as human food; it is well regarded for its high adaptability to adverse agro-climatic conditions and for its chemical composition, which contains high levels of fibers, minerals and bioactive compounds, such as phenolic

*e-mail: onesiomelo@gmail.com compounds. ${ }^{1}$ Sorghum provides nutritional benefits, even with a low availability of proteins. ${ }^{2}$

The phenolic compounds present in sorghum grains, such as tannins, have functional groups in their structures, such as hydroxyls, that enable formation of complexes along with the proteins through the formation of covalently hydrophobic interactions; these are mainly hydrogen bonds with the amides and carbonyl groups of those molecules. ${ }^{3}$ However, thermal processing, such as thermoplastic extrusion, can burst those bonds and interactions, resulting in an increase of protein availability and, consequently, an improvement in the cereal's nutritional quality. ${ }^{4}$ 
The extrusion process combines various parameters, such as speed of screw rotation, mechanical shear, temperature, moisture and pressure; and generates numerous chemical modifications and reactions, such as protein denaturation, enzymatic and microorganisms inactivation, starch gelatinization and liberation of complexed phenolic compounds. ${ }^{5}$ Despite these possible alterations being knowing, we have little information about this thermal procedure with respect to the profile of chemical constituents present in the food matrix; in other words, sugar molecules, flavonoids, phenolic acids and amino acids.

For understanding of sorghum chemical profile, many techniques have been used, including gas chromatography attached to mass spectrometry (CG-MS) ${ }^{6}$ electrophoresis in polyacrylamide gel (SDS-PAGE) ${ }^{7}$ and high-performance liquid chromatography with evaporative light scattering detector (ELSD) detector. ${ }^{8}$ All of those techniques, however, require extensive laboratory preparation, lengthy analysis and high operational costs, making it difficult to perform them. ${ }^{9}$

Therefore, with the continuous improvement of mass spectrometry (ESI/MS), it has increasingly become the most sensible option. In this analysis, the ionization source is of utmost importance, as there is no standard for all samples. ${ }^{10}$ The most recent ionization method is by spray in paper (PSI), which is performed in ambient conditions, capable of better preserving the characteristics of the samples. This technique consists of applying high tension to a chromatographic paper added to a solvent, what generates ions from the studied analyte and enables the acquisition of digital impressions in a wide range of masses in short analysis times, thus contributing to the characterization of complex food matrices. ${ }^{11,12}$ Given these characteristics, the use of ESI/MS with PSI is a viable way to assess the effect of extrusion on the chemical profile of matrices such as sorghum.

The purpose of this study is to assess the effects of thermoplastic extrusion with regard to the chemical composition and to the total phenolic compounds, as well as assess the impact of this process on phenolic acids, flavonoids, sugar, amino acids and other chemical constituents of sorghum grains, using paper spray mass spectrometry (PS-MS) and with the aid of the main components analysis (PCA).

\section{Experimental}

Reagents

The standard catechin hydrates, Folin-Ciocalteu, 2,2 diphenyl-1-picryl-hidrazil (DPPH), 2,2' -azino- bis-3-ethylbenzothiazoline-6-sulfonic acid (ABTS), 2,4,6-tris(2-pyridyl)-s-triazine (TPTZ) and 6-hydroxy2,5,7,8-tetramethylchromane-2-carboxylic acid (Trolox) was acquired from Sigma Aldrich (St. Louis, MO, USA). Gallic acid was acquired from NEON (São Paulo, SP, Brazil). The reagents of analytical grade acetone, chloroform, ethanol and hydrochloric acid were acquired from Vetec (São Paulo, SP, Brazil). The chromatographic paper used was acquired from Whatman (Little Chalfont, Buckinghamshire, United Kingdom).

\section{Sorghum samples}

Grains of two Brazilian sorghum genotypes, BRS 332 red pericarp and non-pigmented testa (no tannins) and SC 319, of brown pericarp and pigmented testa (with tannins, also called proanthocyanidins), provided according to the germplasm bank standard of Embrapa Milho e Sorgo (Brazilian Agricultural Research Corporation) in Sete Lagoas, Minas Gerais, Brazil, were used in the studies.

Cultivation occurred during the 2015-2016 harvest at Embrapa Milho e Sorgo experimental fields in Sete Lagoas, Minas Gerais, Brazil, located at $19^{\circ} 27^{\prime} 54^{\prime \prime}$ 'south latitude and $44^{\circ} 14^{\prime} 79^{\prime}$ " west longitude, following a space of $0.5 \mathrm{~m}$ between the rows and a density of 8 to 10 plants per square meter, using N-P-K fertilizer (nitrogen, phosphorus and potassium) of formula 08-28-16.

The harvest happened in July 2016 and the selected grains were sieved and stored at $-18{ }^{\circ} \mathrm{C}$. Subsequently the grains were grounded in a Marconi mill (São Paulo, Brazil) for $2 \mathrm{~min}$ and sieved in sieves of $0.5 \mathrm{~mm}$ aperture (60 mesh), obtaining raw flours that were kept under cooling $\left(10 \pm 2{ }^{\circ} \mathrm{C}\right)$ until its use.

\section{Thermoplastic extrusion}

The extruded samples were acquired by Embrapa Agroindústria de Alimentos (Brazilian Agricultural Research Corporation), Rio de Janeiro-RJ, Brazil, from raw flours subjected to thermoplastic extrusion following the process described by Vargas-Solorzano et al. ${ }^{13}$ An extruder Evolum HT 25 (Clextral, Firminy, France) had been used, co-rotational model and twin-screw of constant speed of $600 \mathrm{rpm}$, with a relation (length $\times$ diameter) of 40:1, and 10 temperature zones $(30,30,60,90,100,100,120,120$, $\left.150,150{ }^{\circ} \mathrm{C}\right)$.

\section{Color}

The color parameters were determined using the equipment Hunter-Lab (color Flex EZ, $45^{\circ} / 0^{\circ}$, USA). 
The calibration was performed using a standard white calibration plate and the color had been expressed in the CIE-Lab as L* (whiteness/blackness), a* (redness/green) and $b^{*}$ (yellow/blue). For each sample, three measurements had been made.

\section{Chemical composition}

The determination of moisture, proteins, lipids, fibers and ashes levels was performed according to the methodologies described by the Association of Official Analytical Chemists (AOAC) ${ }^{14}$ with the carbohydrates being determined by difference.

\section{Extractable polyphenols}

The acquisition of extractable polyphenols was performed according to the methodology described by Rufino et al. ${ }^{15}$ To that, $0.5 \mathrm{~g}$ of sample and $1 \mathrm{~mL}$ of methanol/water (50:50, v/v) were added in an Eppendorf tube of $2 \mathrm{~mL}$. After $1 \mathrm{~h}$ of incubation at room temperature, the tubes were centrifuged for $15 \mathrm{~min}$ at $25406 \times \mathrm{g}$ and the recovered supernatant were stored in a $5 \mathrm{~mL}$ volumetric flask. To the precipitate, $1.0 \mathrm{~mL}$ of acetone/water (70:30, v/v) were added, and incubation and centrifugation procedures were repeated under the same conditions described above, the second supernatant obtained was mixed to the first in the volumetric flask, the volume being filled with deionized water.

Hydrolysable polyphenols and non-extractable proanthocyanins

The preparation of the sample containing the nonextractable polyphenols, the hydrolysable polyphenols and the non-extractable proanthocyanins was performed according to the methodology described by Hartzfeld et al. ${ }^{16}$ and Arranz et al. ${ }^{17}$ using the remaining precipitate from the methanol/acetone extraction. For the hydrolysable polyphenols, $0.2 \mathrm{~g}$ of the precipitate and $4 \mathrm{~mL}$ of methanol/ $\mathrm{H}_{2} \mathrm{SO}_{4}(90: 10 \mathrm{v} / \mathrm{v})$ were added in $15 \mathrm{~mL}$ Falcon tubes, after $20 \mathrm{~h}$ of incubation at $85{ }^{\circ} \mathrm{C}$ the supernatant was collected in a volumetric flask of $5 \mathrm{~mL}$ and the volume made up with deionized water. To obtain non-extractable proanthocyanins, $0.2 \mathrm{~g}$ of the precipitate were added with $4 \mathrm{~mL}$ of butanol $/ \mathrm{HCl}$ (97.5:2.5 v/v) and $0.28 \mathrm{~g}$ of $\mathrm{FeCl}_{3}$ in $15 \mathrm{~mL}$ Falcon tube after $1 \mathrm{~h}$ at $100{ }^{\circ} \mathrm{C}$, the tubes were centrifuged at $2500 \times \mathrm{g}$ for $10 \mathrm{~min}$ and the supernatant were collected in a $5 \mathrm{~mL}$ volumetric flask, the residue were then washed twice with butanol and the supernatants combined in the volumetric flask, making up to volume with deionized water.

\section{Phenolic compounds and antioxidant activity}

The extracts obtained were used for quantification of the total phenolic compounds level and for determination of antioxidant activity using three methodologies (ABTS, ferric reducing antioxidant power (FRAP), DPPH). The phenolic compounds level was determined by the methodology of Singleton, Orthofer and Lamuela-Raventós, ${ }^{18}$ and the antioxidant capacity by ABTS and FRAP methods, following Rufino et al., ${ }^{15}$ and by the DPPH methodology described by the AOAC protocol. ${ }^{14}$

\section{Chemical profile by paper spray mass spectrometry}

The determination of sorghum sampling profiles, in both positive and negative modes, was performed following the methodology described by Silva et al. ${ }^{12}$ using an LCQ Fleet (Thermo Scientific, San Jose, CA, USA) mass spectrometer attached to an ionization source in paper spray. To perform the analysis, a piece of chromatography paper cut in the shape of an equilateral triangle $(1.5 \mathrm{~cm})$ was used and placed in the metal connector and positioned at a distance of $0.5 \mathrm{~cm}$ from the mass spectrometer entrance using a mobile platform (XYZ). The equipment was connected to a high-voltage source through a copper wire (Figure 1).

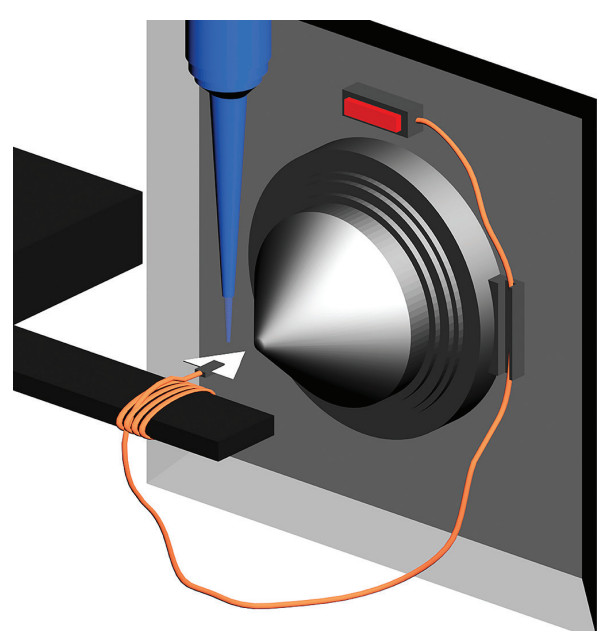

Figure 1. Illustrative image that represents ionization source for paper spray diagram.

At the end of the chromatographic paper triangle were applied $0.2 \mu \mathrm{L}$ of the polyphenols extracted from the samples and $40 \mu \mathrm{L}$ of methanol. The voltage supply was then activated for data acquisition. The samples were analyzed in triplicates in both ionization modes (positive and negative). The ions, and its fragments obtained by the end of the analysis, were identified by data described in the literature.

The operational parameters used were: PS-MS supply voltage equal to $+4 \mathrm{kV}$ (positive ionization mode) and 
$-3 \mathrm{kV}$ (negative ionization mode); capillary voltage of $40 \mathrm{~V}$; transfer tube temperature of $275{ }^{\circ} \mathrm{C}$; lenses tube voltage of $120 \mathrm{~V}$; and mass range from 100 to $1000 \mathrm{~m} / z$ (positive ionization mode) and from 100 to $1000 \mathrm{~m} / \mathrm{z}$ (negative ionization mode). The ramming energies to fragment the compounds varied from 15 to $30 \mathrm{eV}$.

\section{Statistical analysis}

The physical-chemical and antioxidant activity analysis results were assessed by the Student's $t$-test $(\alpha=0.05)$. The correlations between the total phenolic compounds and antioxidant activities were obtained through Pearson's coefficient correlation $(\alpha=0.05)$. The mass spectra were analyzed by the software Xcalibur (Thermo Fisher Scientific Inc.), and the PS-MS medium spectra in both positive and negative ionization modes were set using an Excel 2016 spreadsheet. The principal component analysis (PCA) was performed with eight samples, two raw and two extrusions from each genotype (SC 319 and BRS 332) with three replicates, using the software MATLAB, ${ }^{19}$ with the aid of PLS Toolbox. ${ }^{20}$

\section{Results and Discussion}

Color

The values obtained for the color parameters $\left(\mathrm{L}^{*}\right.$, $\left.a^{*}, b^{*}\right)$ are shown in Table 1 . It was observed that the extrusion process affected all of the evaluated parameters, increasing factor $\mathrm{a}^{*}$ by $83.78 \%$, and $\mathrm{b}^{*}$ by $40.91 \%$. As for the $\mathrm{L}^{*}$ criteria, there were declines of $28.33 \%$ and $10.41 \%$, respectively, for genotypes SC 319 and BRS 332. The data

Table 1. Mean results of the color parameters of the raw and extruded sorghum grains of genotypes BRS 332 and SC 319

\begin{tabular}{lccc}
\hline \multirow{2}{*}{ Parameter } & \multirow{2}{*}{ Genotype } & \multicolumn{2}{c}{ Sorghum } \\
\cline { 3 - 4 } & & Raw & Extruded \\
\hline L $^{*}$ & BRS 332 & $74.61 \pm 0.13^{\mathrm{aA}}$ & $66.85 \pm 0.11^{\mathrm{aB}}$ \\
& SC 319 & $66.38 \pm 0.23^{\mathrm{bA}}$ & $47.58 \pm 0.78^{\mathrm{bB}}$ \\
\hline \multirow{2}{*}{$\mathrm{a}^{*}$} & BRS 332 & $5.61 \pm 0.08^{\mathrm{aA}}$ & $8.57 \pm 0.03^{\mathrm{aB}}$ \\
\hline & SC 319 & $6.39 \pm 0.07^{\mathrm{bA}}$ & $11.74 \pm 0.35^{\mathrm{bB}}$ \\
\hline $\mathrm{b}^{*}$ & BRS 332 & $13.76 \pm 0.22^{\mathrm{aA}}$ & $19.39 \pm 0.07^{\mathrm{aB}}$ \\
& SC 319 & $11.51 \pm 0.15^{\mathrm{bA}}$ & $14.87 \pm 0.31^{\mathrm{bB}}$ \\
\hline
\end{tabular}

Raw: raw sorghum; extruded: extruded sorghum; L: whiteness/blackness; a: redness/green; b: yellow/blue; BRS 332: red pericarp sorghum with no pigmented testa; SC 319: brown pericarp sorghum with pigmented testa. Averages followed by lowercase letters in the same column, within the same parameters, do not differ to a 5\% probability by the Student's $t$-test. Averages followed by capital letters in the same line do not differ to a 5\% probability by the Student's $t$-test. found were consistent with the darker colors observed in the extruded samples.

The decline in the values of $\mathrm{L}^{*}$ indicates that there was a darkening of flours after the extrusion process, fact that can be attributed to the high levels of protein and reduced sugars present in the sorghum samples, which might react in high temperature conditions occurring in the Maillard Reaction (non-enzymatic darkening). Furthermore, during the extrusion process, anthocyanin molecules are damaged, which might result in darker products, also arising from the Maillard Reaction. ${ }^{4,21}$

The use of high temperatures, such as in thermoplastic extrusion, causes the oxidation of pigments present in the food matrices of cereals, which leads to pigment production in shades of brown. This formation lowers the values of $\mathrm{L}^{*}$ and boosts those of $a^{*}$ and $b^{*}{ }^{22}$ Similar data were described by Jafari et al..$^{23}$ who analyzed sorghum flours.

\section{Centesimal composition}

The extrusion process contributed to reducing the moisture levels of the raw samples from 10.72 to $8.75 \%$ (SC 319) and from 10.84 to $8.75 \%$ (BR 332), these reductions being 18.38 and $29.15 \%$, respectively. The dryer samples allow for longer storage, with lower risk of contamination by microorganisms. ${ }^{24}$ Despite the changes, all of the samples comply with the flours legislation, which requires a maximum moisture of $15 \% .^{25}$

However, for the other nutrients, the extrusion permitted growth of fiber and carbohydrate levels and reduced lipid and ash levels (Table 2). Although the extrusion had not affected the total protein content from the analyzed samples, we know that this process improves protein digestibility through denaturation of their structures, resulting in conformational changes and exposure of sites susceptible to enzymatic action. ${ }^{26}$

The rise in carbohydrate levels can be assigned to a greater proportion of dry matter in the extruded samples, since this parameter had been determined by difference. With regards to carbohydrates, especially starches, it is important to highlight that extrusion, through shearing levels and high temperatures, results in partial or complete shattering and gelatinization of the granules promoting sorghum grain starch digestibility. ${ }^{27}$

The increased levels of fibers from the extruded samples can be explained by the formation of resistant starch and indigestible glucans through the processes of gelatinization and starch downgrading and through the transglucosidation reactions that occur during the extrusion, increasing the levels of insoluble fibers. ${ }^{28}$ In addition, during the extrusion process reactions, such as the Maillard Reaction, 
Table 2. Chemical composition of raw and extruded sorghum, on dry basis, of genotypes BRS 332 and SC 319

\begin{tabular}{lccc}
\hline \multirow{2}{*}{ Parameter / $\%$} & Genotype & \multicolumn{2}{c}{ Sorghum } \\
\cline { 3 - 4 } & & Raw & Extruded \\
\hline \multirow{2}{*}{ Proteins } & BRS 332 & $14.17 \pm 0.70^{\mathrm{aA}}$ & $13.98 \pm 0.36^{\mathrm{aA}}$ \\
& SC 319 & $13.12 \pm 0.57^{\mathrm{aA}}$ & $12.81 \pm 0.05^{\mathrm{bA}}$ \\
\hline \multirow{2}{*}{ Carbohydrates } & BRS 332 & $67.58 \pm 1.16^{\mathrm{aA}}$ & $70.76 \pm 0.25^{\mathrm{aB}}$ \\
& SC 319 & $64.67 \pm 0.89^{\mathrm{bA}}$ & $66.97 \pm 0.06^{\mathrm{bB}}$ \\
\hline \multirow{2}{*}{ Lipids } & BRS 332 & $3.09 \pm 0.07^{\mathrm{aA}}$ & $1.42 \pm 0.03^{\mathrm{aB}}$ \\
& SC 319 & $2.21 \pm 0.12^{\mathrm{bA}}$ & $1.18 \pm 0.01^{\mathrm{bB}}$ \\
\hline \multirow{2}{*}{ Fiber } & BRS 332 & $11.94 \pm 0.50^{\mathrm{aA}}$ & $12.58 \pm 0.04^{\mathrm{aB}}$ \\
& SC 319 & $16.85 \pm 0.34^{\mathrm{bA}}$ & $17.45 \pm 0.01^{\mathrm{bB}}$ \\
\hline \multirow{2}{*}{ Ash } & BRS 332 & $3.12 \pm 0.08^{\mathrm{aA}}$ & $1.26 \pm 0.09^{\mathrm{aB}}$ \\
& SC 319 & $3.16 \pm 0.13^{\mathrm{aA}}$ & $1.59 \pm 0.02^{\mathrm{bB}}$ \\
\hline
\end{tabular}

Values on a dry basis (\%). Raw: raw sorghum; extruded: extruded sorghum; BRS 332: red pericarp sorghum with no pigmented testa; SC 319: brown pericarp sorghum with pigmented testa. Averages followed by lowercase letters in the same column, within the same parameters, do not differ to a $5 \%$ probability by the Student's $t$-test. Averages followed by capital letters in the same line do not differ to a $5 \%$ probability by the Student's $t$-test.

there are associations of covalent interactions among the macromolecules that result in insoluble complexes; these can be accounted as fibers because they are not digested by digestive enzymes. ${ }^{29}$

The decline of lipid levels can be ascribed to the formation of fatty acid complexes and amylose. During the extrusion, due to high temperature and moisture, the starch structure is modified because its amorphous and crystalline regions start exposing more of the amylose molecules during the gelatinization process. ${ }^{30}$ The greater exposure of the amylose molecules allows the lipid hydrocarbon portion to intersperse the helical structure of amylose, resulting in the formation of more difficult complexes to be extracted. ${ }^{31}$

The decrease of ash content could be due to the high temperatures used during the extrusion that alter the conformational structure of the macromolecules, especially in the proteins, generating destabilization and rupture of existing connections between the micronutrients, like the minerals, and these molecules, resulting in the loss of such components during the process. ${ }^{32}$

The values observed for the extruded samples of both genotypes, SC 319 and BRS 332, are in agreement with other studies, such as those from Arbex et al. ${ }^{33}$ and Lopes et al. ${ }^{34}$ where sorghum grains were extruded in relation to carbohydrates (71.04 and 58.16\%), proteins (11.26 and $12.20 \%)$, lipids (0.41 and $2.30 \%)$, ashes (1.87 and $1.38 \%)$ and fibers (8.84 and $14.59 \%)$, and the differences were attributed to the different genotypes of the studies and climatic conditions that interfere with nutrient deposition..$^{35}$

The nutritional characteristics of the evaluated sorghum genotypes resemble the most traditional cereals, like corn, wheat and rice. ${ }^{36,37}$ The inclusion of those cereals in human nutrition is of great interest, especially the extruded ones, that present greater availability of proteins and provide better starch and protein digestibility. ${ }^{38,39}$

\section{Total phenolic compounds and antioxidant activity}

The effects caused by extrusion on the total phenolic compounds contents, extractible and bonded in comparison to the raw samples of genotypes SC 319 and BRS 332, are shown on Table 3. Regardless of the genotype, the extrusion process significantly increased the fractions of phenolic compounds, as well as their antioxidant capacities. Statistical differences were observed among the assessed parameters regarding genotypes SC 319 and BRS 332, and these can be ascribed to the genetic differences among the sorghum varieties, such as the presence of pigmented forehead containing tannins in sorghum SC 319.

The use of sorghum was beneficial because it allowed for a significant increase of phenolic compounds in all of the fractions. For extractible phenolic compounds, this increase was 39.40\% (SC 319) and 48.22\% (BRS 332); for bonded phenolic compounds, 19.94\% (SC 319) and $22.52 \%$ (BRS 332), and for total phenolic compounds, $35.09 \%$ (SC 319) and $41.87 \%$ (BRS 332), in comparison to raw samples. The increases can be assigned to extrusion performed in low moisture products $(<15 \%)$ that generate high shearing rates; and these, in combination with high temperatures and screws high rotation speed, break the food matrices' cell wall more intensely, resulting in depolymerization of condensed tannins and liberation of other combined phytochemicals. ${ }^{40,41}$

The extrusion treatment has affected the proportion of each phenolic compound fraction with respect to total phenolics, as shown in Figure 2.

For the extruded samples, the extractable fractions represented $80.36 \%$ (SC319) and $72.77 \%$ (BRS 332) of the total, 2.52\% (SC 319) and 5.56\% (BRS 332) more than the raw samples. As a result, there was a decline in the bonded phenolic percentage, proving that extrusion results in liberation of combined phenolic compounds, making them extractible. The same behavior was observed in the work of Zhang et al. ${ }^{42}$ who had verified that extruded rice grains have significantly higher phenolic content than raw grains, and that the extractable fractions of the extruded samples are more representative than the raw ones. 
Table 3. Total phenolic compounds, antioxidant activities, in dry basis, of raw and extruded genotypes BRS 332 and SC 319

\begin{tabular}{|c|c|c|c|c|}
\hline \multirow{2}{*}{ Parameter } & \multirow{2}{*}{ Portion } & \multirow{2}{*}{ Genotype } & \multicolumn{2}{|c|}{ Sorghum } \\
\hline & & & Raw & Extruded \\
\hline \multirow{6}{*}{ Total phenolic compounds / (mg AGE g $\left.{ }^{-1}\right)$} & \multirow{2}{*}{ EPC } & BRS 332 & $3.38 \pm 0.04^{\mathrm{aA}}$ & $5.01 \pm 0.05^{\mathrm{aB}}$ \\
\hline & & SC 319 & $10.94 \pm 0.16^{\mathrm{bA}}$ & $15.25 \pm 0.16^{\mathrm{bB}}$ \\
\hline & \multirow{2}{*}{ BPC } & BRS 332 & $1.11 \pm 0.01^{\mathrm{aA}}$ & $1.36 \pm 0.01^{\mathrm{aB}}$ \\
\hline & & SC 319 & $3.11 \pm 0.01^{\mathrm{bA}}$ & $3.73 \pm 0.05^{\mathrm{bB}}$ \\
\hline & \multirow{2}{*}{ TPC } & BRS 332 & $4.49 \pm 0.06^{\mathrm{aA}}$ & $6.37 \pm 0.05^{\mathrm{aB}}$ \\
\hline & & SC 319 & $14.05 \pm 0.15^{\mathrm{bA}}$ & $18.98 \pm 0.12^{\mathrm{bB}}$ \\
\hline \multirow{6}{*}{ ABTS / $\left(\mu \mathrm{M}\right.$ trolox $\left.\mathrm{g}^{-1}\right)$} & \multirow{2}{*}{$\mathrm{EF}$} & BRS 332 & $34.36 \pm 0.24^{\mathrm{aA}}$ & $54.02 \pm 1.76^{\mathrm{aB}}$ \\
\hline & & SC 319 & $108.11 \pm 5.10^{\mathrm{aA}}$ & $145.84 \pm 1.87^{\mathrm{aB}}$ \\
\hline & \multirow{2}{*}{$\mathrm{BF}$} & BRS 332 & $10.30 \pm 0.08^{\mathrm{aA}}$ & $13.00 \pm 0.18^{\mathrm{aB}}$ \\
\hline & & SC 319 & $23.90 \pm 0.45^{\mathrm{bA}}$ & $28.52 \pm 0.56^{\mathrm{bB}}$ \\
\hline & \multirow{2}{*}{ total } & BRS 332 & $44.66 \pm 0.23^{\mathrm{bA}}$ & $67.02 \pm 1.59^{\mathrm{bB}}$ \\
\hline & & SC 319 & $132.01 \pm 1.37^{\mathrm{bA}}$ & $174.36 \pm 2.41^{\mathrm{bB}}$ \\
\hline \multirow{6}{*}{ FRAP / $\left(\mathrm{mM} \mathrm{Fe}^{2+} \mathrm{g}^{-1}\right)$} & \multirow{2}{*}{$\mathrm{EF}$} & BRS 332 & $10.02 \pm 0.27^{\mathrm{aA}}$ & $14.70 \pm 0.02^{\mathrm{aB}}$ \\
\hline & & SC 319 & $24.61 \pm 1.53^{\mathrm{aA}}$ & $40.39 \pm 1.32^{\mathrm{aB}}$ \\
\hline & \multirow{2}{*}{$\mathrm{BF}$} & BRS 332 & $3.21 \pm 0.08^{\mathrm{aA}}$ & $4.06 \pm 0.09^{\mathrm{aB}}$ \\
\hline & & SC 319 & $8.75 \pm 0.04^{\mathrm{bA}}$ & $11.68 \pm 0.19^{\mathrm{bB}}$ \\
\hline & \multirow{2}{*}{ total } & BRS 332 & $13.23 \pm 0.30^{\mathrm{bA}}$ & $18.76 \pm 0.09^{\mathrm{bB}}$ \\
\hline & & SC 319 & $33.36 \pm 1.54^{\mathrm{bA}}$ & $52.07 \pm 1.15^{\mathrm{bB}}$ \\
\hline \multirow{2}{*}{$\mathrm{DPPH} /\left(\mu \mathrm{M}\right.$ trolox $\left.\mathrm{g}^{-1}\right)$} & \multirow{2}{*}{ total } & BRS 332 & $29.80 \pm 0.85^{\mathrm{aA}}$ & $34.95 \pm 2.20^{\mathrm{aB}}$ \\
\hline & & SC 319 & $42.75 \pm 2.02^{\mathrm{bA}}$ & $59.37 \pm 0.58^{\mathrm{bB}}$ \\
\hline
\end{tabular}

Raw: raw sorghum; extruded: extruded sorghum; AGE: equivalent gallic acid; ABTS: 2,2'-azino-bis-3-ethylbenzothiazoline-6-sulfonic acid; FRAP: ferric reducing antioxidant power; DPPH: 2,2 diphenyl-1-picryl-hidrazil; EPC: extractible phenolic compounds; BPC: bonded phenolic compounds; TPC: total phenolic compounds; EF: extractable fraction; BF: bonded fraction; BRS 332: red pericarp sorghum with no pigmented testa; SC 319: brown pericarp sorghum with pigmented testa. Averages followed by lowercase letters in the same column, within the same parameters, do not differ to a 5\% probability by the Student's $t$-test. Averages followed by capital letters in the same line do not differ to a 5\% probability by the Student's $t$-test.

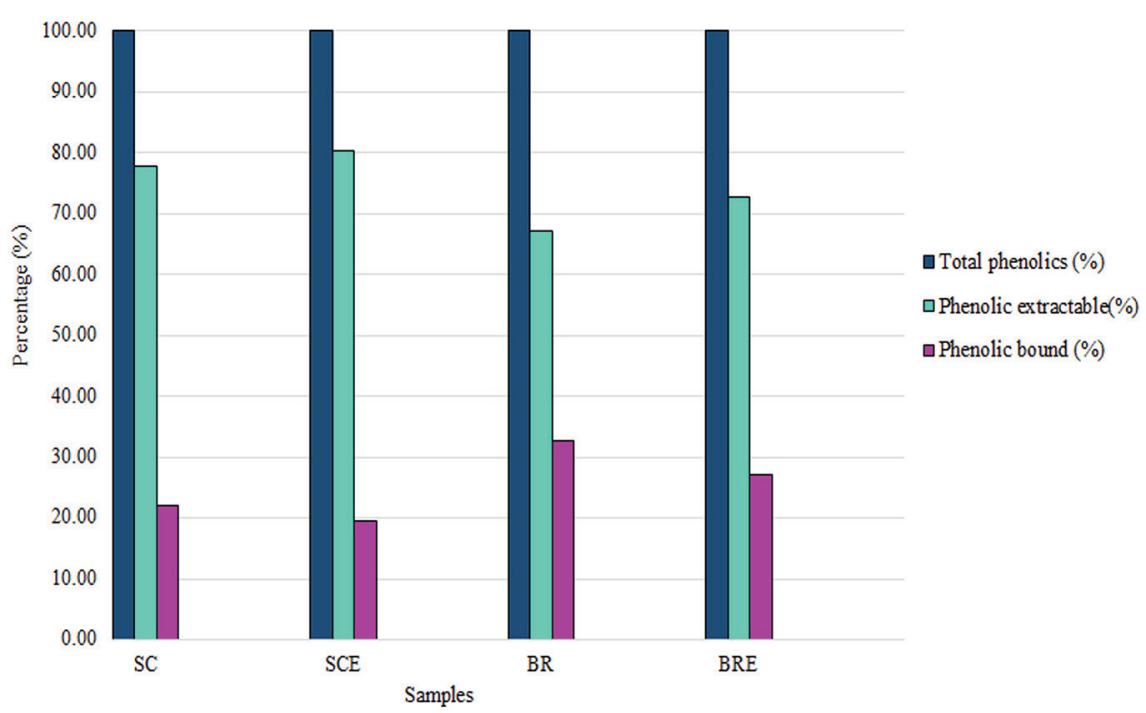

Figure 2. Representation of phenolic compounds proportions in relation to the total. SC: raw sorghum of genotype SC 319; SCE: extruded sorghum of genotype SC 319; BR: raw sorghum of genotype BRS 332; BRE: extruded sorghum of genotype BRS 332. 
An increase in antioxidant capacity was observed in the extruded samples (32.08\% (SC 319) and 50.06\% (BRS 332) by the ABTS methodology, $56.09 \%$ (SC 319) and $41.80 \%$ (BRS 332) by the FRAP method and 39\% (SC 319) and $17 \%$ (BRS 332) by the DPPH technique in relation to the raw samples, which leads to the understanding that the higher phenolic constituents release during extrusion reflects positively on the antioxidant activity of the samples.

The values found for antioxidant activity agree with other work on extruded sorghum grains, such as Hou et al. ${ }^{43}$ The data expressed in Table 3 shows an intense and positive correlation between the total phenolic compounds content and the antioxidant activities ABTS $(r=0.968)$, FRAP $(r=0.994)$ and DPPH $(r=0.951)$, as well as between
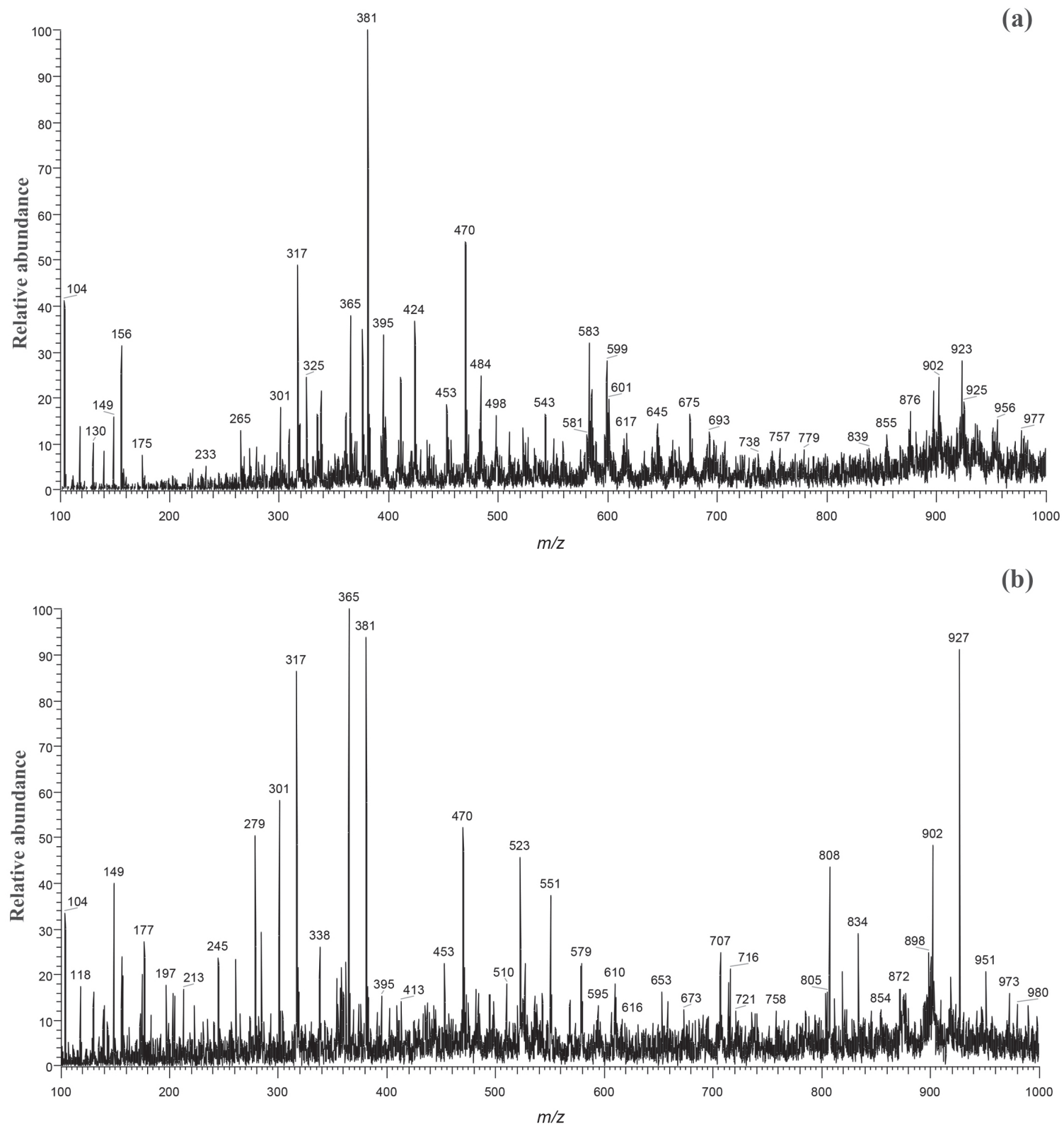

Figure 3. Representation of (a) (+)PS-MS of a raw sample, (b) (+)PS-MS of an extruded sample (BRS 332). methodologies namely, ABTS and FRAP ( $r=0.975)$; ABTS and DPPH $(r=0.963)$; DPPH and FRAP $(r=0.994)$.

The values found for phenolic compounds and antioxidant activity in sorghum grains are higher than those observed for other cereals, ${ }^{44,45}$ suggesting an incorporation of sorghum in human nutrition, especially the extruded forms which present a higher functional potential, for health benefits.

\section{PS-MS chemical profile}

Examples of spectra (PS-MS) of chemical profiles of sorghum, raw and extruded, in positive mode, are shown in Figure 3. Flavonoids, phenolic acids, amino acids and sugars were potentially identified.

(a) (b) 
The extrusion process positively influenced the detection of chemical compounds in the genotypes SC 319 and BRS 332, promoting a greater identification of compounds in the extruded samples, mainly of SC 319.

In the positive ionization mode, 2 more compounds were observed in the extruded samples; and in the negative mode, 18 additional compounds. This result corroborates the previous information, which reported that thermoplastic extrusion exposes of more the food matrix, resulting in a greater release of chemical compounds. With respect to genotypes, in both ionization modes, it was observed that some compounds were only detected in the SC 319 genotype. This may be related to the presence of tannin in this variety and to the fact that most of the phenolic compounds are present in the outer layers of the grain, such as the pigmented forehead, this region being only present in SC $319 .{ }^{46}$

\section{(+)PS-MS fingerprints}

The analysis of the sorghum grains by mass spectrometry with environmental ionization by paper spray allowed for the identification of several classes of chemical constituents. In all samples, seven flavones, two flavonols, one sugar and three amino acids were identified. The possible compounds identified in the positive ionization mode on fingerprints are described in Table 4.
In the extruded samples, specifically in the SC 319 extruded sorghum, two compounds were not identified in the others, a flavone, apigenin mono- $C$-glycoside $(\mathrm{m} / \mathrm{z} 433)$ and a cinnamic acid, $N$-( $\rho$-coumaroyl)- $N$ '-feruloyl spermidine $(\mathrm{m} / \mathrm{z} 468)$. Comparing the genotypes, it was observed that a flavone, Schaftoside $(\mathrm{m} / \mathrm{z}, 565)$ belonging to apigenins was identified only in genotype SC 319 , both in the raw and the extruded forms.

In the flavones, the luteolins together with the apigenins were the constituents of this group predominant in sorghum grains, thus highlighting the compounds glycosylated $(\mathrm{m} / \mathrm{z}, 477)$ and $(\mathrm{m} / \mathrm{z}, 903)$ identified in the present study. ${ }^{57,58}$ In the group of flavonols, the most prominent molecules in cereals, including sorghum, are glycosylated derivatives of quercetins, kaempferol and myricetin, thus highlighting the presence of 3-O-methylquercetin $(\mathrm{m} / \mathrm{z} 317)$, known as isorhamnetin and formed by the methylation of quercetin, and myricetin-hexose $(\mathrm{m} / \mathrm{z}, 597)$, a glycosylated form of myricetin in the present study. ${ }^{59}$

The mentioned flavonoids are secondary metabolites of polyphenolic structures with distinct residues bonded to phenolic rings, which are widely associated with several beneficial health effects, since they have antioxidant, anticancer, anti-inflammatory, anti-viral, cardioprotective and other functions. ${ }^{60}$

In the sorghum samples, three amino acids were identified, but arginine $(\mathrm{m} / \mathrm{z}, 175)$ was highlighted, as its

Table 4. Compounds identified in sorghum samples by (+)PS-MS

\begin{tabular}{|c|c|c|c|c|c|c|c|}
\hline \multirow{2}{*}{ Tentatively identification } & \multirow{2}{*}{$\mathrm{m} / \mathrm{z}$} & \multirow{2}{*}{ MS/MS } & \multicolumn{4}{|c|}{ Sample } & \multirow{2}{*}{ Reference } \\
\hline & & & SC & SCE & BR & BRE & \\
\hline Glycine betaine & 118 & 59 & $\times$ & $x$ & $x$ & $x$ & 47 \\
\hline Histidine & 156 & 110 & $\times$ & $x$ & $x$ & $x$ & 48,49 \\
\hline L-Arginin & 175 & 116 & $x$ & $x$ & $x$ & $x$ & 49 \\
\hline 3-O-Methylquercetin & 317 & $301 ; 274 ; 273$ & $x$ & $x$ & $x$ & $x$ & 50 \\
\hline Sucrose & 381 & $201 ; 219$ & $\times$ & $x$ & $x$ & $x$ & 12 \\
\hline Apigenin mono- $C$-glycoside & 433 & $361 ; 349 ; 337 ; 323$ & nd & $x$ & nd & nd & 51 \\
\hline$C$-Hexosyl-chrysoeriol & 463 & $445 ; 427 ; 409 ; 391 ; 379 ; 343 ; 301$ & $x$ & $x$ & $x$ & $x$ & 51 \\
\hline$N$-( $\rho$-Coumaroyl)- $N$ '-feruloyl spermidine & 468 & $177 ; 451$ & nd & $x$ & nd & nd & 52 \\
\hline 4,5-Dimethylluteolin-8- $C$-glucoside & 477 & $327 ; 411$ & $\times$ & $\times$ & $x$ & $\times$ & 53 \\
\hline Tricin $O$-hexoside & 493 & 331 & $\times$ & $x$ & $x$ & $x$ & 51 \\
\hline Schaftoside (apigenin- $6 C$-glucoside- $8 C$-arabinoside) & 565 & $379 ; 457 ; 469 ; 481 ; 511 ; 529 ; 547$ & $x$ & $x$ & nd & nd & 54 \\
\hline 6,8-Di- $C$ - $\beta$-glucopyranosyl chrysin & 579 & $561 ; 525$ & $x$ & $x$ & $x$ & $x$ & 50,55 \\
\hline$C$-Hexosyl- $C$-pentosyl-luteolin & 581 & $299 ; 353 ; 395 ; 509 ; 545 ; 563$ & $\times$ & $x$ & $\times$ & $\times$ & 51 \\
\hline Myricetin-hexose & 597 & 319 & $\times$ & $x$ & $\times$ & $x$ & 56 \\
\hline$C$-Hexosyl-luteolin- $O$-hexoside- $O$-pentoside & 743 & $431 ; 611 ; 743$ & $\times$ & $x$ & $\times$ & $x$ & 51 \\
\hline$O, C$-ramnosyl-glycosyl-apigenin $O, O$ dihexoside & 903 & $739 ; 271$ & $\times$ & $x$ & $x$ & $x$ & 51 \\
\hline
\end{tabular}

SC: raw sorghum of genotype SC 319; SCE: extruded sorghum of genotype SC 319; BR: raw sorghum of genotype BRS 332; BRE: extruded sorghum of genotype BRS 332. nd: not detected. 
presence in sorghum grains may affect the post-processing staining of this cereal. The same is true in the case of the extruded samples, since the amino acid residue of arginine as well as that of lysine effectively participate in the Maillard Reaction. ${ }^{61}$

\section{(-)PS-MS fingerprints}

Of the possible chemical compounds identified in fingerprints in the negative ionization mode (Table 5), twenty-three were present in all samples (six cinnamic acids, eight flavones, one flavanone, two flavonols, two flavan-3-oys, one anthocyanin, two propane glycerides and one sugar), nine were present in both extruded samples (one benzoic acid, three flavones, three flavan3 -oys, one flavonol and one glyceride propane), nine exclusively in extruded sorghum SC 319 (four benzoic acids, one cinnamic acid, one flavone, one flavan-3-ol and two flavonols), and eight in the raw and extruded SC 319 samples (three cinnamic acids, one flavone, one flavanone, two flavan-3-oys and a flavonol).

The sugar identified in all samples was sucrose $(\mathrm{m} / \mathrm{z}$ 377), a carbohydrate that, together with starch, is predominant in sorghum grains. The accumulation of sugar in sorghum varieties is related to defensive mechanisms in stress situations, which guarantees the metabolic activities of plant and grain development. ${ }^{75}$

In the present study, phenolic acids predominant in sorghum grains were detected, including three cinnamic acids, caffeic acid $(\mathrm{m} / \mathrm{z}, 179), \rho$-coumaric acid $(\mathrm{m} / \mathrm{z}, 165)$ and ferulic acid $(\mathrm{m} / \mathrm{z}, 193)$, in addition to the chlorogenic acid, caffeoylquinic acid $(\mathrm{m} / \mathrm{z}, 353)$, and its 3,5-di$O$-caffeoylquinicacidmethylester derivative $(\mathrm{m} / \mathrm{z}, 535)$, and a benzoic acid, protocatechic acid $(\mathrm{m} / \mathrm{z}, 153){ }^{76}$

Cinnamic acids are found whole or combined with other molecules such as glucose, esters and other acids, the most common being chlorogenic acid, a combination of quinic and caffeic acid. Benzoic acids can also be found in both forms, but their conjugated form mainly occurs with glycosides. ${ }^{77}$ The most common hydroxycinnamic acids are caffeic, $\rho$-coumaric and ferulic acids; and benzoic acids are protocatechic, gallic, siringeic, vanillic, gallic acids, all of them already related to antidiabetic, anti-inflammatory and antioxidant functions. ${ }^{78,79}$

In the class of flavonoids, the subclasses flavones, flavanones, flavan-3-oys, flavonols and anthocyanins were identified. The presence of the apigenin-6- $C$-glucoside $(\mathrm{m} / \mathrm{z} 431)$ and luteolin-7-O-glucoside $(\mathrm{m} / \mathrm{z} 447)$ flavones reaffirm the abundance of these groups in sorghum grains. ${ }^{57}$ Another important feature of the flavone group

Table 5. Compounds identified in sorghum samples by (-)PS-MS

\begin{tabular}{|c|c|c|c|c|c|c|c|}
\hline \multirow{2}{*}{ Tentatively identification } & \multirow{2}{*}{$m / z$} & \multirow{2}{*}{ MS/MS } & \multicolumn{4}{|c|}{ Sample } & \multirow{2}{*}{ Reference } \\
\hline & & & $\mathrm{SC}$ & SCE & $\mathrm{BR}$ & BRE & \\
\hline Isomer of hydrobenzoic acid & 137 & 93 & nd & $x$ & nd & nd & 62 \\
\hline Vanillin & 151 & $123 ; 136$ & nd & $x$ & nd & $x$ & 62 \\
\hline Protocatechic acid & 153 & 109 & nd & $x$ & nd & nd & 63 \\
\hline$\rho$-Coumaric acid & 165 & $119 ; 147$ & $x$ & $x$ & nd & nd & 62 \\
\hline Isomer of vanillic acid & 167 & 123 & nd & $x$ & nd & nd & 62 \\
\hline Caffeic acid & 179 & 135 & $x$ & $x$ & $x$ & $x$ & 64,65 \\
\hline Dihydro-caffeic acid & 181 & 137 & $x$ & $x$ & nd & nd & 63,66 \\
\hline Ferulic acid & 193 & $134 ; 149 ; 178$ & $x$ & $x$ & nd & nd & 63 \\
\hline Hydroxy benzyl malic acid (Eucomicacid) & 239 & $195 ; 179 ; 177 ; 149 ; 133$ & nd & $x$ & nd & nd & 67 \\
\hline Apigeninidin & 253 & $179 ; 209 ; 225$ & $x$ & $x$ & $x$ & $x$ & 68 \\
\hline 1-O-Dihydrocaffeoyl glycerol & 255 & $135 ; 136 ; 137 ; 161 ; 162 ; 163 ; 179$ & $x$ & $x$ & $x$ & $x$ & 63 \\
\hline Coumaroyl aspartic acid & 278 & $260 ; 234 ; 216$ & $x$ & $x$ & $x$ & $x$ & 62 \\
\hline Luteolin & 285 & $\begin{array}{c}165 ; 167 ; 175 ; 191 ; 197 ; 199 \\
201 ; 213 ; 217 ; 223 ; 239 ; 241 \\
243 ; 257 ; 267\end{array}$ & $x$ & $x$ & nd & nd & 63 \\
\hline Catechin & 289 & $125 ; 179 ; 205 ; 231 ; 245$ & $x$ & $x$ & nd & nd & 63 \\
\hline Quercetin & 301 & $179 ; 151$ & $x$ & $x$ & nd & nd & 69 \\
\hline Epigallocatechin & 305 & $125 ; 179 ; 219 ; 261$ & $x$ & $x$ & nd & nd & 65,70 \\
\hline Isorhamnetin & 315 & 300 & nd & $x$ & nd & nd & 63 \\
\hline Tricin & 329 & 314 & $x$ & $x$ & $x$ & $x$ & 63 \\
\hline
\end{tabular}


Table 5. Compounds identified in sorghum samples by (-)PS-MS (cont.)

\begin{tabular}{|c|c|c|c|c|c|c|c|}
\hline \multirow{2}{*}{ Tentatively identification } & \multirow{2}{*}{$m / z$} & \multirow{2}{*}{ MS/MS } & \multicolumn{4}{|c|}{ Sample } & \multirow{2}{*}{ Reference } \\
\hline & & & $\mathrm{SC}$ & SCE & BR & BRE & \\
\hline Glucose isomer of galoyl & 331 & $125 ; 169$ & nd & $x$ & nd & nd & 62 \\
\hline Caffeoyl quinic acid & 353 & $179 ; 191$ & $x$ & $x$ & $x$ & $x$ & 63 \\
\hline Curcumina & 367 & $134 ; 149 ; 173 ; 217$ & $x$ & $x$ & $\times$ & $x$ & 62 \\
\hline Sucrose & 377 & 341 & $x$ & $x$ & $\times$ & $x$ & 12,71 \\
\hline 1,3-O-Dicaffeoyglycerol & 415 & $135 ; 161 ; 179 ; 253$ & $x$ & $x$ & $x$ & $\times$ & 63 \\
\hline 1,3-O-Caffeoyl-dihydrocaffeoylglycerol & 417 & $162 ; 254 ; 255$ & nd & $x$ & nd & $x$ & 63 \\
\hline Apigenin-6- $C$-glucoside (isovitexin) & 431 & $269 ; 341$ & $x$ & $x$ & $\times$ & $\times$ & 63 \\
\hline Naringenin hexoside II & 433 & $271 ; 313 ; 415$ & $x$ & $x$ & $x$ & $x$ & 63 \\
\hline Taxifolin- $O$-pentoside & 435 & $285 ; 303 ; 399$ & $x$ & $x$ & $x$ & $x$ & 70 \\
\hline Luteolin-7-O-glucoside & 447 & $285 ; 327$ & $x$ & $x$ & $x$ & $x$ & 72 \\
\hline Dihydrokaempferol hexoside & 449 & $269 ; 287 ; 329 ; 405$ & $x$ & $x$ & $x$ & $x$ & 63 \\
\hline Catechin hexoside & 451 & 289 & nd & $x$ & nd & $\times$ & 63 \\
\hline Caffeic acid derivative & 459 & $383 ; 281 ; 251 ; 161$ & $x$ & $x$ & $x$ & $x$ & 71 \\
\hline Chrysoeryolhexoside & 461 & $299 ; 341$ & $x$ & $x$ & $\times$ & $x$ & 63 \\
\hline Quecertinhexoside & 463 & 301 & nd & $x$ & nd & $x$ & 63 \\
\hline Taxifolin hexoside & 465 & $177 ; 259 ; 285 ; 303 ; 447$ & $\times$ & $x$ & $x$ & $x$ & 63 \\
\hline (Epi) gallocatechin hexose & 467 & $423 ; 329$ & nd & $\times$ & nd & $\times$ & 67 \\
\hline Apigenin 6,8-di- $C$ arabinoside & 533 & $473 ; 443$ & nd & $x$ & nd & $\times$ & 73 \\
\hline 3,5-Di- $O$-caffeoylquinicacidmethylester & 535 & $517 ; 475 ; 445 ; 415 ; 373 ; 253$ & $\times$ & $x$ & $x$ & $x$ & 74 \\
\hline 6- $C$-Pentosyl-8- $C$-pentosylluteolin & 549 & $369 ; 429 ; 459 ; 489 ; 531$ & $\times$ & $\times$ & $\times$ & $x$ & 72 \\
\hline 6- $C$-Pentosyl-8- $C$-hexosylapigenin & 563 & $\begin{array}{c}545 ; 503 ; 473 ; 443 ; 425 ; 413 ; \\
383 ; 353\end{array}$ & $x$ & $\times$ & $\times$ & $x$ & 72 \\
\hline $\begin{array}{l}\text { X"-O-Rhamnosyl } C \text {-(6-deoxy-pentohexos-ulosyl) } \\
\text { luteolin }\end{array}$ & 575 & $531 ; 429 ; 411 ; 367$ & nd & $x$ & nd & nd & 72 \\
\hline (Epi)catechin-(Epi)catechin (procyanidin B IV) & 577 & $451 ; 425 ; 407 ; 289 ; 287$ & $\times$ & $x$ & $x$ & $x$ & 64,67 \\
\hline 6- $C$-Hexosyl-8- $C$-pentosyl Luteolin & 579 & $\begin{array}{c}561 ; 519 ; 489 ; 459 ; 441 ; 429 \\
399 ; 369\end{array}$ & nd & $x$ & nd & $x$ & 72 \\
\hline Quercetin-3-O-arabinoglycoside & 595 & 301 & nd & $\times$ & nd & $x$ & 69 \\
\hline $\begin{array}{l}\text { Luteolin-8- } C \text {-glucoside-7- } O \text {-glucoside (orientin-7- } \\
O \text {-glucoside) }\end{array}$ & 609 & $447 ; 327$ & $\times$ & $\times$ & $x$ & $x$ & 73 \\
\hline Eriodictyol-di-C-dihexoside & 611 & $593 ; 575 ; 491 ; 473 ; 287$ & $x$ & $x$ & nd & nd & 67 \\
\hline (Epi) catechin-3-O-dihexoside isomer & 613 & $451 ; 433 ; 289 ; 245$ & nd & $x$ & nd & $x$ & 62 \\
\hline Tricin-7-O-glucoside- 4"-O-rhamnoside & 637 & $491 ; 329$ & $x$ & $x$ & $x$ & $x$ & 73 \\
\hline Kaempferol 3-rutinoside-7-rhamnoside & 739 & 593 & nd & $x$ & nd & nd & 62 \\
\hline Quercetin di-deoxyhexose & 755 & 446 & nd & $x$ & nd & nd & 67 \\
\hline
\end{tabular}

SC: raw sorghum of genotype SC 319; SCE: extruded sorghum of genotype SC 319; BR: raw sorghum of genotype BRS 332; BRE: extruded sorghum of genotype BRS 332; nd: not detected.

is the tricin constituent $(\mathrm{m} / \mathrm{z}, 329)$, which is a metabolite present in cereals and correlated with several actions such as antioxidants and anti-inflammatory drugs. ${ }^{80}$

In the flavonols, taxifolin hexoside $(\mathrm{m} / \mathrm{z}, 435)$ is indicated in some varieties of sorghum as the most abundant polyphenol. ${ }^{81}$ Among the flavanones, it is evident that the narigenins, such as naringenin hexoside II $(\mathrm{m} / \mathrm{z} 433)$, together with erythriois and its derivatives, are the main flavanones found in sorghum grains. ${ }^{82}$

In the flavan-3-ol subclass the compounds catechin $(\mathrm{m} / \mathrm{z}, 289)$, catechin hexoside $(\mathrm{m} / \mathrm{z}, 289)$, epigallocatechin $(\mathrm{m} / \mathrm{z} 305)$ and epigallocatechin hexose $(\mathrm{m} / \mathrm{z}, 467)$ were noted. The catechins and the epigallocatechins are geometric isomers that present two benzene rings interconnected 
by a pyran ring, having a trans and cis configuration, respectively, and presenting different bioactivities. ${ }^{83}$ In sorghum grains, catechins represent a large proportion of total phenolic compounds. ${ }^{84}$

The 3-deoxyanthiocyanidins are the anthocyanins found exclusively in sorghum grains, constituted by luteolinidine and apigeninidina, and are responsible for the coloring of the grain. Their molecules do not have a hydroxyl in the $\mathrm{C} 3$ position, which results in greater thermal stability and $\mathrm{pH}$ variations and allows for use as a natural dye. ${ }^{64}$ Apigeninidine $(\mathrm{m} / \mathrm{z} 253)$, identified in the present work, is found at various concentrations in black, brown and red pericarp sorghum. ${ }^{65}$

Three poorly known compounds were identified in the present work: 1-O-dihydrocaffeoylglycerol $(\mathrm{m} / z, 255)$, 1,3-O-dicaffeoyglycerol $(\mathrm{m} / \mathrm{z}, 415)$ and 1,3-O-caffeoyldihydrocaffeoylglycerol $(\mathrm{m} / \mathrm{z} 417)$, all of which belong to the class of the phenylpropane glycerides, which are glycerol esters of phenolic acids. These compounds were mentioned as being one of the sources of phenolic acids in sorghum grains in the work of Salazar-Lopez et al. ${ }^{46}$ and identified in the studies of Kang et al. ${ }^{63}$ and Wu et al. ${ }^{66}$ with sorghum grains.

The chemical constituents mentioned above presented bioactive beneficial health functions, such as high antioxidant capacity, ${ }^{79}$ anti-inflammatory, ${ }^{1}$ antibacterial, ${ }^{85}$ antifungal,${ }^{80}$ antiviral ${ }^{86}$ and anticancer actions,${ }^{87}$ which demonstrates the cumulative functional potential of all chemical compounds present in the rich and complex food matrix that is sorghum.

\section{Principal component analysis (PCA)}

In addition to the identification of chemical constituents, a principal component analysis was performed between the raw and extruded samples of the SC 319 and BRS 332
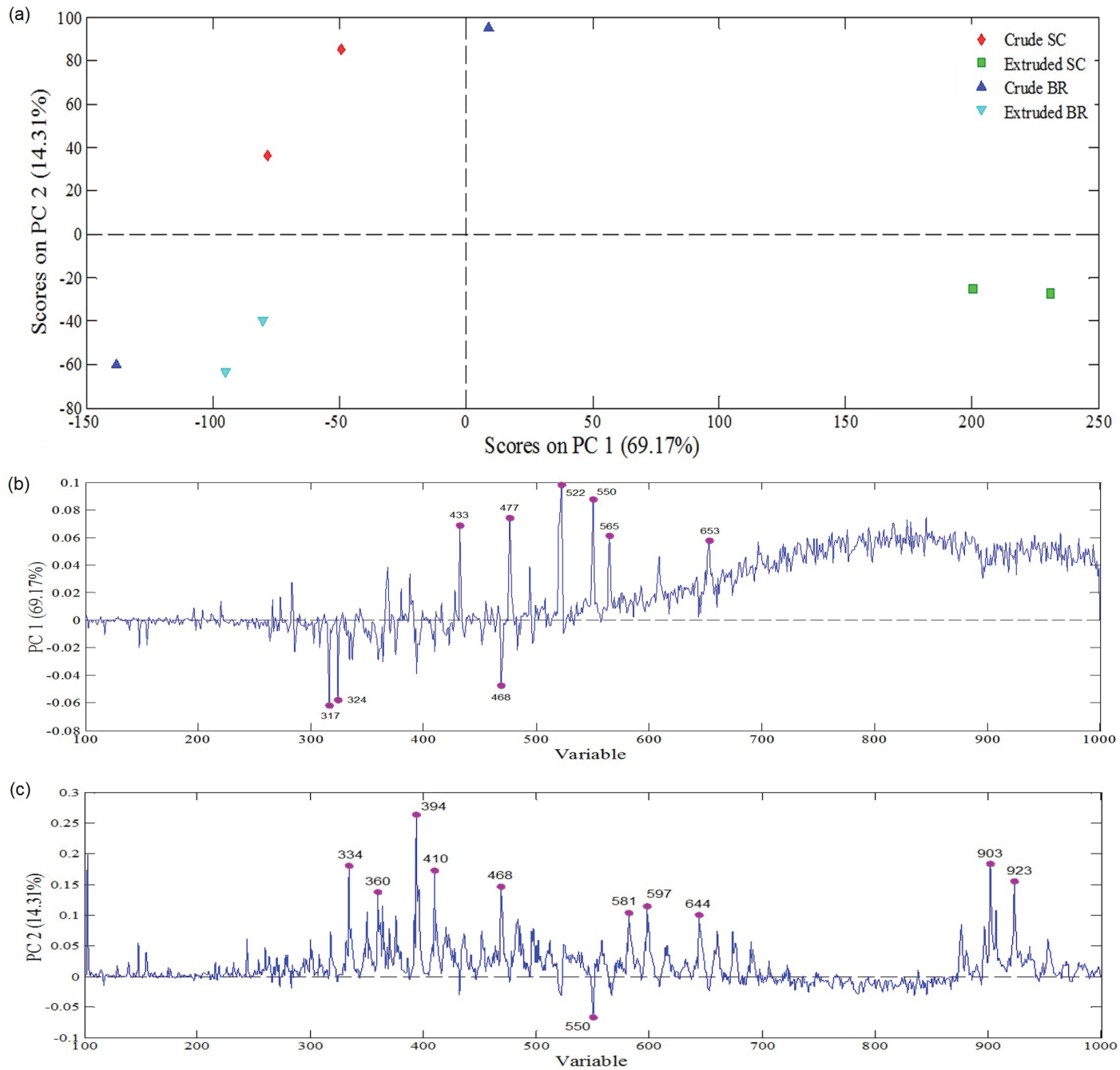

Figure 4. $\mathrm{PC} 1$ and $\mathrm{PC} 2$ scoring in the positive ionization modes. (a) Representation of the loadings responsible for the discrimination of the sample scores in (b) PC 1 and (c) PC 2. Raw SC: raw sorghum of the SC 319 genotype. Extruded SC: sorghum extruded from genotype SC 3190. Raw BR: raw sorghum of genotype BRS 332. Extruded BR: sorghum extruded from BRS 332 genotype. 
genotypes. The generation of data matrices using the mass spectra in the positive and negative ionization modes, (+)PS-MS and (-)PS-MS, two main component models were obtained.

The obtained models were elaborated by choosing two main components (PC1 and $\mathrm{PC} 2)$, which explained respectively $83.48 \%$ (positive ionization mode) and $91.94 \%$ (negative ionization mode) of total data variability, noting the difference between the samples due to the extrusion treatment and to the genotype.

The chemical components detected in the positive ionization mode (Figure 4) allowed for the differentiation of SC 319 and BRS 332 genotypes. PC1 (69.17\% data variability) separated the SC (positive score) and the extruded BR $(\mathrm{m} / \mathrm{z}, 317,324$ and 468 negative values), and this differentiation is possible through the generation of ions $m / z$ 433, 477, 522, 550, 565 and 653 (positive score). PC2 (14.31\% data variability) evidenced the discrimination of all raw samples of SC (positive score) and of some raw samples BR (negative score) through $\mathrm{m} / \mathrm{z}, 334,360,394$, 410, 468, 581, 597, 644, 903 and 923 (positive score) and 550 (negative score).

In the negative ionization mode, the detected compounds allowed for discrimination of the samples by the treatment (Figure 5). PC1 (66.21\% of the data variability) separated the SC 319 and BRS 332 (positive score) genotypes from the SC 319 and BRS 332 sorghum samples; their behavior was due to $m / z 142,156,193,377,415,438,535,718$ and 780 (positive score) and $\mathrm{m} / \mathrm{z}$ ions 278 and 558 (negative score).

The PC1 and PC2 loads in the positive ionization mode (Figure 4), as well as those in PC1 and PC2 in negative ionization mode (Figure 5), demonstrate the differences between the models derived mainly from the chemical constituents 3-O-methylquercetin, apigenin mono $C$-glucoside, $N$-( $\rho$-coumaroyl)- $N$ '-feruloylspermidine, 4,5-dimethyl-8-C-glucoside, schaftoside, $C$-hexosyl-
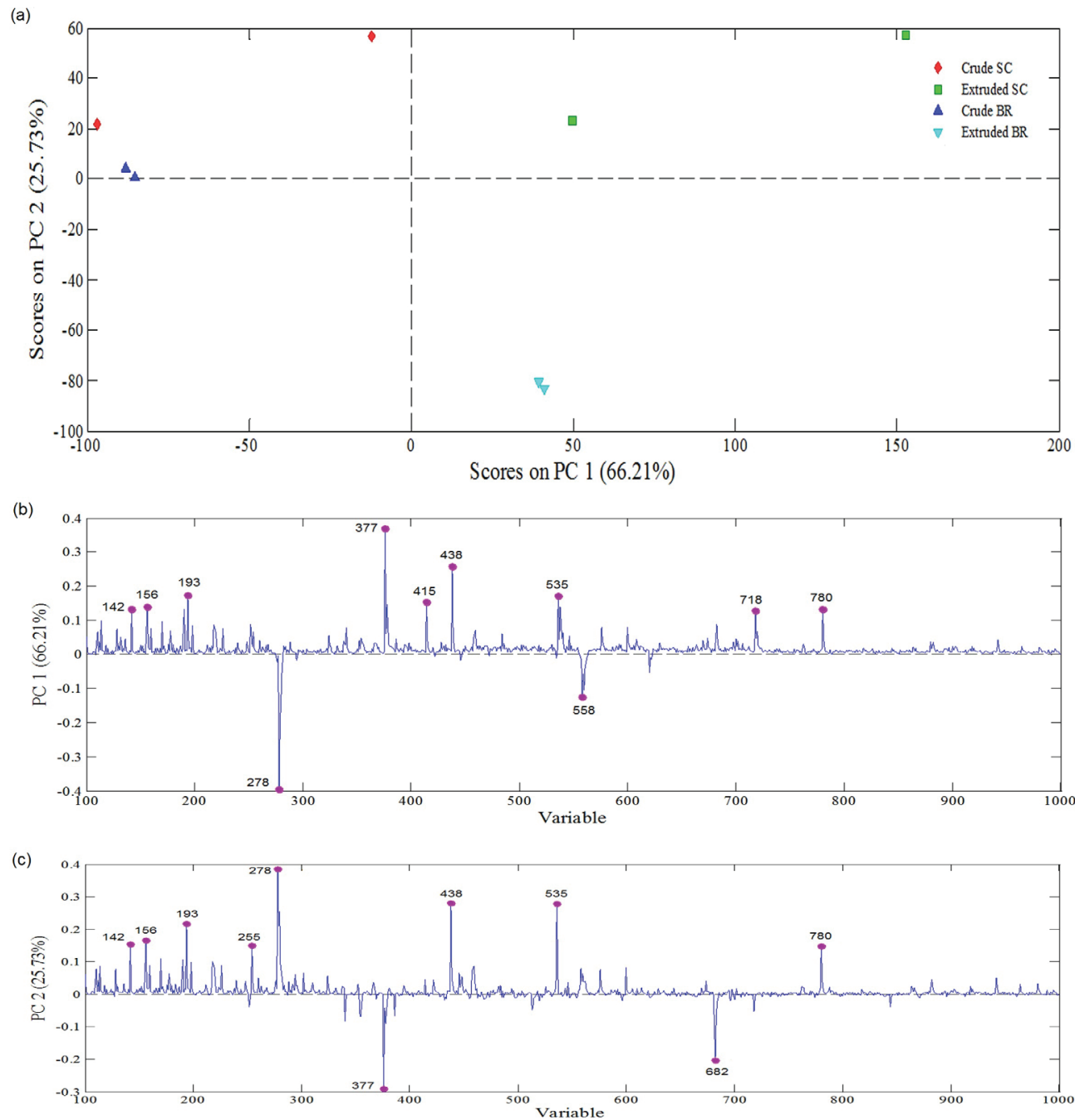

Figure 5. PC1 and PC2 scores in the negative ionization modes (a). Representation of the loadings responsible for the discrimination of the sample scores in (b) PC 1 and (c) PC 2. Raw SC: raw sorghum of the SC 319 genotype. Extruded SC: sorghum extruded from genotype SC 3190. Raw BR: raw sorghum of genotype BRS 332. Extruded BR: sorghum extruded from BRS 332 genotype. 
$C$-pentosyl-luteolin, myrcetin-hexose and $O, C$-ramnosylglycosyl-apigenin- $O, O$-dihexoside identified in the positive ionization mode; and those derived from the compounds ferulic acid, sucrose, 1-O-dihydrocaffeoylglycerol, 1,3-dicycloheglycerol, tricin- $O$-hexoside and coumaroyl aspartic acid detected in the negative ionization mode.

Therefore, the use of PS-MS analysis as well as the analysis of the main components allow for the efficient characterization of the phenolic compounds content of the studied samples, thus demonstrating the effects of extrusion and the specific genetic characteristics of each sorghum genotype through rapid, inexpensive analyses.

\section{Conclusions}

The use of thermoplastic extrusion produced positive effects on the nutritional characteristics of sorghum grains; it increased the fiber content, favored starch digestibility and made proteins, including the genotype containing tannin (SC 319), more available.

The extrusion process increased the release of total phenolic compounds, as evidenced by the reduction of the levels of phenolic compounds bound, the increase in the concentration of extractable phenolic compounds, and the greater identification of phenolic compounds in the extruded samples. Predominantly, the flavonoids of the classes of flavones, flavonols and phenolic acids, portrayed in the profile of chemical constituents of the extruded sorghum, allow us to conclude that this treatment is able to improve the availability of compounds with bioactive characteristics, thus constituting an advantage in relation to untreated raw sorghum.

\section{Supplementary Information}

Supplementary information are available free of charge at http://jbcs.sbq.org.br as PDF file.

\section{Acknowledgments}

The authors thank CNPq and CAPES for financial support.

\section{References}

1. Cardoso, L. M.; Pinheiro, S. S.; Martino, H. S. D.; PinheiroSant'ana, H. M.; Crit. Rev. Food Sci. Nutr. 2017, 57, 379.

2. Anunciação, P. C.; Cardoso, L. M.; Gomes, J. V. P.; Lucia, C. M. D.; Carvalho, W. P.; Galdeano, M. C.; Queiroz, V. A. V.; Alfenas, R. C. G.; Martino, H. S. D.; Pinheiro-Sant'ana, H. M.; Food Chem. 2017, 221, 984.
3. Dunn, K. L.; Yang, L.; Girard, A.; Bean, S.; Awika, J. M.; J. Agric. Food Chem. 2015, 63, 1234.

4. Buitimea-Cantua, N.; Gutierrez-Uribe, J. A.; Serna-Saldivar, S. O.; J. Med. Food 2018, 21, 188.

5. Moreno, C. R.; Fernandez, P. C. R.; Rodriguez, E. O. C.; Carrillo, J. M.; Rochin, S. M. In Extrusion of Metals, Polymers, and Food Products; IntechOpen, 2018, DOI: 10.5772/ intechopen.68753.

6. Khakimov, B.; Jespersen, B. M.; Engelsen, S. B.; Foods 2014, 3,569 .

7. Yi, C.; Li, Y.; Ping, J.; J. Texture Stud. 2017, 48, 386.

8. Hums, M. E.; Moreau, R. A.; Powell, M. J.; Hoyt, J. L.; J. Am. Oil Chem. Soc. 2018, 95, 845.

9. Zhi-Ping, Z.; Xiao-Ning, L.; Ya-Jun, Z.; Chin. J. Anal. Chem. 2014, 42, 145.

10. Alberici, R. M.; Simas, R. C.; Sanvido, G. B.; Romão, W.; Lalli, P. M.; Benassi, M.; Cunha, I. B. S.; Eberlin, M. N.; Anal. Bioanal. Chem. 2010, 398, 265.

11. Gomez-Rios, G. A.; Reyes-Garces, N.; Bojko, B.; Pawliszyn, J.; Anal. Chem. 2016, 88, 1259.

12. Silva, M. R.; Freitas, L. G.; Souza, A. G.; Araújo, R. L. B.; Lacerda, I. C. A.; Pereira, H. V.; Augustini, R.; Melo, J. O. F.; J. Braz. Chem. Soc. 2019, 30, 1034.

13. Vargas-Solorzano, J. W.; Carvalho, C. W. P.; Takeiti, C. Y.; Ascheri, J. L. R.; Queiroz, V. A. V.; Food Res. Int. 2014, $55,37$.

14. Association of Official Analytical Chemistry (AOAC); Official Methods of Analysis, 19 ${ }^{\text {th }}$ ed.; AOAC: Gaithersburg, Maryland, USA, 2018.

15. Rufino, M. S. M.; Alves, R. E.; Brito, E. S.; Perez-Jimenez, J.; Saura-Calixto, F.; Mancini-Filho, J.; Food Chem. 2010, 121, 996.

16. Hartzfeld, P. W.; Forkner, R.; Hunter, M. D.; Hagerman, A. E.; J. Agric. Food Chem. 2002, 50, 1785.

17. Arranz, S.; Saura-Calixto, F.; Shaha, S.; Kroon, P. A.; J. Agric. Food Chem. 2009, 57, 7298.

18. Singleton, V. L.; Orthofer, R.; Lamuela-Raventós, R. M.; Methods Enzymol. 1999, 299, 152.

19. MATLAB, version 7.9.0.529; Mathworks: Natick, MA, USA, 2009.

20. PLS Toolbox, version 5.2.2; Eigenvectors Research: Manson, WA, USA, 2009.

21. Nayak, B.; Berrios, J. D. J.; Powers, J. R.; Tang, J.; J. Food Sci. 2011, 76, C874.

22. Carneiro, O. S.; Covas, J. A.; Vergnes, B.; J. Appl. Polym. Sci. 2000, 78, 1419.

23. Jafari, M.; Koocheki, A.; Milani, E.; J. Cereal Sci. 2017, 75, 324.

24. Wahab, B. A.; Adebowale, A. R. A.; Sanni, S. A.; Sobukola, O. P.; Obadina, A. O.; Kajihausa, O. E.; Adegunwa, M. O.; Sanni, L. O.; Tomlins, K.; Food Sci. Nutr. 2016, 4, 50. 
25. Ministério da Agricultura, Pecuária e Abastecimento (MAPA); Instrução Normativa No. 8: Regulamento Técnico de Identidade e Qualidade da Farinha de Trigo; Diário Oficial da União (DOU), Brasília, No. 105, de 03/06/2005.

26. Chaidez-Laguna, L. D.; Torres-Chavez, P.; Ramirez-Wong, B.; Marquez-Rios, E.; Islas-Rubio, A. R.; Carvajal-Millan, E.; J. Cereal Sci. 2016, 69, 351.

27. Koa, S. S.; Jin, X.; Zhang, J.; Sopade, P. A.; J. Cereal Sci. 2017, $75,314$.

28. Robin, F.; Schuchmann, H. P.; Palzer, S.; Trends Food Sci. Technol. 2012, 28, 23.

29. Vasanthan, T.; Gaosong, J.; Yeung, J.; Li, J.; Food Chem. 2002, 77,35 .

30. Chao, C.; Yu, J.; Wang, S.; Copeland, L.; Wang, S.; J. Agric. Food Chem. 2018, 66, 272.

31. Panyo, A. E.; Emmambux, M. N.; Starch 2017, 69, DOI: 10.1002/star.201600203.

32. Chantada-Vazquez, M. P.; Moreda-Pineiro, A.; Barciela-Alonso, M. C.; Barmejo-Berrera, P.; Appl. Spectrosc. Rev. 2017, 52, 145.

33. Arbex, P. M.; Moreira, M. E. C.; Toledo, R. C. L.; Cardoso, L. M.; Pinheiro-Sant'ana, H. M.; Benjamin, L. A.; Licursi, L.; Carvalho, C. W. P.; Queiroz, V. A. A.; Martino, H. S. D.; J. Funct. Foods 2018, 42, 346.

34. Lopes, R. C. S. O.; Lima, S. L. S.; Silva, B. P.; Toledo, R. C. L.; Moreira, M. E. C.; Anunciação, P. C.; Walter, E. H. M.; Carvalho, C. W. P.; Queiroz, V. A. V.; Ribeiro, A. Q.; Martino, H. S. D.; Food Res. Int. 2018, 107, 629.

35. Babujia, L. C.; Silva, A. P.; Biondo, P. B. F.; Garcia, J. C.; Mandarino, J. M. G.; Visentainer, J. V.; Acta Sci., Agron. 2015, 37,463 .

36. Fraser, K.; Collete, V.; Hancock, K. R.; J. Agric. Food Chem. 2016, 64, 6676.

37. Patil, S. P.; Arya, S. S.; J. Food Meas. Charact. 2017, 11, 1284.

38. Tian, J.; Ogawa, Y.; Shi, J.; Chen, S.; Zhang, H.; Liu, D.; Ye, X.; Crit. Rev. Food Sci. Nutr. 2018, 5, DOI: 10.1080/10408398.2018.1484341.

39. Weerasooriya, D. K.; Bean, S. R.; Nugusu, Y.; Loerger, B. P.; Tesso, T. T.; PLoS One 2018, 13, DOI: 10.1371/journal. pone.0203005.

40. Dlamini, N. R.; Taylor, J. R. N.; Rooney, L. W.; Food Chem. 2007, 105, 1412.

41. Ti, H.; Zhang, R.; Zhang, M.; Wei, Z.; Chi, J.; Deng, Y.; Zhang, Y.; Food Chem. 2015, 178, 186.

42. Zhang, R.; Khan, S. A.; Chi, J.; Wei, Z.; Zhang, Y.; Deng, Y.; Liu, L.; Zhang, M.; J. Food Sci. Technol. 2018, 88, 64.

43. Hou, F.; Su, D.; Xu, J.; Gong, Y.; Zhang, R.; Wei, Z.; Chi, J.; Zhang, M.; J. Food Process. Preserv. 2016, 40, 1171.

44. Rochetti, G.; Chiodelli, G.; Giuberti, G.; Masoero, F.; Trevisan, M.; Lucini, L.; Food Chem. 2017, 228, 367.

45. Giordano, D.; Locatelli, M.; Travaglia, F.; Bordiga, M.; Reyneri,
A.; Coisson, J. D.; Blandino, M.; Food Chem. 2017, 233, 483.

46. Salazar-Lopez, N. J.; Gonzalez-Aguilar, G.; Rouzaud-Sandez, O.; Robles-Sanchez, M.; J. Food Sci. Technol. 2018, 38, 369.

47. Servillo, L.; Onofrio, N.; Giovane, A.; Casale, R.; Cautela, D.; Ferrari, G.; Castaldo, D.; Balestrieri, M. L.; Food Chem. 2018, 239, 234.

48. Ozcan, S.; Senyuva, H. Z.; J. Chromatogr. A 2006, 1135, 179.

49. Gogichaeva, N. V.; Williams, T.; Alterman, M. A.; J. Am. Soc. Mass Spectrom. 2007, 18, 279.

50. Gobbo-Neto, L.; Lopes, N. P.; J. Agric. Food Chem. 2008, 56, 1193.

51. Cavaliere, C.; Foglia, P.; Pastorini, E.; Samperi, R.; Lagana, A.; Rapid Commun. Mass Spectrom. 2005, 19, 3143.

52. Handrick, V.; Vogt, T.; Frolov, A.; Anal Bioanal Chem. 2010 , 398, 2789.

53. Colombo, R.; Yariwake, J. H.; Queiroz, E. F.; Ndjoko, K.; Hostettmann, K.; Phytochem. Anal. 2006, 17, 337.

54. Galland, M.; Boutet-Mercey, S.; Lounifi, I.; Godin, B.; Balzergue, S.; Grandjean, O.; Morin, H.; Perreau, F.; Debeaujon, I.; Rajjou, L.; Plant Cell Physiol. 2014, 55, 1646.

55. Gobbo-Neto, L.; Gates, P. J.; Lopes, N. P.; Rapid Commun. Mass Spectrom. 2008, 22, 3802.

56. Abu-Reidah, I.; Ali-Shtayeh, M. S.; Jamous, R. M.; ArraezRoman, D.; Segura-Carretero, A.; Food Chem. 2015, 166, 179.

57. Nabavi, S. F.; Braidy, N.; Gortzi, O.; Sobarzo-Sanchez, E.; Daglia, M.; Skalicka-Wozniak, K.; Nabavi, S. M.; Brain Res Bull. 2015, 119, 1.

58. Cardoso, L. M.; Pinheiro, S. S.; Carvalho, C. W. P.; Queiroz, V. A. V.; Menezes, C. B.; Moreira, A. V. B.; Barros, F. A. R.; Awika, J. M.; Martino, H. S. D.; Pinheiro-Sant'ana, H. M.; J. Cereal Sci. 2015, 65, 220.

59. PrzybylskaBalcerek, A.; Frankowski, J.; StuperSzablewska, K.; Eur. Food Res. Technol. 2019, 245, 1075.

60. Wang, T. Y.; Li, Q.; Bi, K. S.; Asian J. Pharm. 2018, 13, 12.

61. Deng, Y.; Wierenga, P. A.; Schols, H. A.; Sforza, S.; Gruppen, H.; Food Hydrocolloids 2017, 69, 210.

62. Martini, S.; Conte, A.; Tagliazucchi, D.; Food Res. Int. 2018, 112, DOI: 10.1016/j.foodres.2018.06.020.

63. Kang, J.; Price, W. E.; Ashton, J.; Tapsell, L. C.; Johnson, S.; Food Chem. 2016, 211, 215.

64. Wizi, J.; Wang, L.; Hou, X.; Tao, Y.; Ma, B.; Yang, Y.; Ind. Crops Prod. 2018, 120, 203.

65. Zhang, H.; Jung, J.; Zhao, Y.; Carbohydr. Polym. 2016, 137,82 .

66. Wu, G.; Johnson, S. K.; Bornman, J. F.; Bennett, S. J.; Clarke, M. W.; Singh, V.; Fang, Z.; Sci. Rep. 2016, 24, DOI: 10.1038/ srep21835.

67. Abu-Reidah, I.; Contreras, M. D. M.; Arraez-Roman, D.; Electrophoresis 2014, 35, 1571. 
68. Wu, G.; Bennett, S. J.; Bornman, J. F.; Clarke, M. W.; Fang, Z.; Johnson, A. K.; Food Res. Int. 2017, 97, 347.

69. Iswaldi, I.; Arraez-Roman, D.; Rodriguez-Medina, I.; Beltran-Debon, R.; Joven, J.; Segura-Carretero, A.; Fernandez-Gutierrez, A.; Anal. Bioanal. Chem. 2011, 400, 3643.

70. Jaiswal, R.; Jayasinghe, L.; Kuhnert, N.; J. Mass Spectrom. 2012, 47, 502.

71. Chen, H. J.; Inbaraj, B. S.; Chen, B. H.; Int. J. Mol. Sci. 2012, 13, 260.

72. Figueirinha, A.; Paranhos, A.; Perez-Alonso, J.; Santos-Buelga, C.; Batista, M. T.; Food Chem. 2008, 110, 718.

73. Hussein, S. R.; Latif, R. R. A.; Markouk, M. M.; Elkhateeb, A.; Mohammed, R. S.; Soliman, A. A. F.; Abdel-Hameed, E. S. S.; Chem. Pap. 2018, 72, 29.

74. Sun, Q.; Han, Z.; Wang, L.; Xiong, L.; Food Chem. 2014, 145, 756.

75. Njokweni, A.; Ibraheem, O.; Ndimba, B.; Plant Omics 2016 , 9, 183.

76. Mrid, R. B.; Bouargalne, Y.; Omari, R. E.; Nhiri, M.; J. Rep. Pharm. Sci. 2019, 8, 91.

77. Taofiq, O.; Gonzalez-Paramas, A. M.; Barreiro, M. F.; Ferreira, I. C. F. R.; Molecules 2017, 22, DOI: 10.3390/ molecules22020281.

78. Chandrasekara, A. In Encyclopedia of Food Chemistry; Melton, L.; Shahidi, F.; Varelis, P., eds.; Elsevier: Makandura,
2019, p. 534; Shen, S.; Huang, R.; Li, C.; Wu, W.; Chen, H.; Shi, J.; Chen, S.; Ye, X.; Molecules 2018, 23, DOI:10.3390/ molecules23051203.

79. Li, M.; Pu, Y.; Yoo, C. G.; Ragauskas, A. J.; Green Chem. 2016, 18, 1439.

80. Luo, X.; Cui, J.; Zhang, H.; Duan, Y.; Zhang, D.; Cai, M.; Chen, G.; Ind. Crops Prod. 2018, 112, 296.

81. Massey, A. R.; Reddivari, L.; Radhakrishnan, S.; Charepalli, V.; Hewage, E. K. K.; Ramakrishna, V.; Vanamala, J. K. P.; J. Funct. Foods 2016, 23, 601.

82. Liu, M.; Zheng, Y.; Wang, C.; Xie, J.; Wang, B.; Wang, Z.; Han, J.; Sun, D.; Niu, M.; Food Chem. 2016, 196, 148.

83. Oboh, G.; Adewuni, T. M.; Ademosun, A. O.; Olasehinde, T. A.; Comp. Clin. Pathol. 2016, 25, 749.

84. Devil, P. S.; Saravanakumar, M.; Mohandas, S.; Afr. J. Food Sci. 2012, 6, 567.

85. Ide, K.; Kawasaki, Y.; Kawakami, K.; Yamada, H.; Curr. Med. Chem. 2016, 23, 4773.

86. Zhu, Y.; Shi, Z.; Yao, Y.; Hao, Y.; Ren, G.; Food Agric. Immunol. 2017, 28, 1530.

87. Xiang, L. P.; Wang, A.; Ye, J. H.; Zheng, X. Q.; Polito, C. A.; Lu, J. L.; Li, Q. S.; Liang, Y. R.; Nutrients 2016, 8, 458.

Submitted: June 17, 2019

Published online: October 14, 2019 